\title{
Grain Crops Monitoring in the South Part \\ of Western Siberia Based \\ on the Satellite Images' Data
}

\author{
Liubov A. Sladkikha, \\ Ekaterina N. Kulik ${ }^{\mathrm{b}^{*}}$ and Elena Yu. Sakharova ${ }^{\mathrm{a}, \mathrm{b}}$ \\ ${ }^{a}$ Siberian Center FGBU «SRC «Planeta» \\ 30 Sovetskaya, Novosibirsk, 630099, Russia \\ ${ }^{b}$ Siberian State University of Geosystems and Technologies \\ 10 Plakhotnogo, Novosibirsk, 630108, Russia
}

Received 31.03.2015, received in revised form 09.05.2015, accepted 20.06.2015

The article presents the technology of satellite grain crops' monitoring used in the Siberian Center FGBU «SRC «Planeta». Possible applications of remote sensing data for solving a number of agricultural tasks are examined, as well as the results of target experience for the south of Western Siberia in 2014 are presented.

Keywords: remote sensing, vegetation monitoring, vegetation index.

DOI: $10.17516 / 1999-494 X-2015-8-6-726-733$.

\section{Мониторинг посевов зерновых культур}

\section{юга Западной Сибири}

\section{по данным спутниковых наблюдений}

\author{
Л.А. Сладких ${ }^{\mathrm{a}}$, Е.Н. Кулик ${ }^{\tilde{0}}$ Е.Ю. Сахарова ${ }^{\mathrm{a}, \boldsymbol{\sigma}}$ \\ ${ }^{a}$ Сибирский иентр ФГБУ «НИЦ «Планета» \\ Россия, 630099, Новосибирск, ул. Советская, 30 \\ ${ }^{6}$ Сибирский государственный университет \\ геосистем и технологий \\ Россия, 630108, Новосибирск, ул. Плахотного, 10
}

В статье изложена технология спутникового мониторинга состояния посевов зерновых культур, используемая в Сибирском иентре ФГБУ «НИЦ «Планета». Рассмотрень возможности применения данных дистанционного зондирования Земли для решения ряда

(C) Siberian Federal University. All rights reserved

* Corresponding author E-mail address: e.n.kulik@ssga.ru 
сельскохозяйственных задач, а также представлены результаты проведения работ по этому направлению на юге Западной Сибири за 2014 год.

Ключевые слова: дистанционное зондирование, мониторинг растительности, вегетационный индекс.

\section{Введение}

ФГБУ «НИЦ «Планета» осуществляет оперативное управление и научно-методическое руководство наземным комплексом приёма и обработки спутниковой информации гидрометеорологической службы. ФГБУ «НИЦ «Планета» включает три региональных центра: Европейский (г. Москва, с филиалами в г. Обнинск и г. Долгопрудный), Сибирский (СЦ) (г. Новосибирск) и Дальневосточный (г. Хабаровск). Сибирский центр ФГБУ «НИЦ «Планета» обеспечивает спутниковыми данными и результатами их тематической обработки оперативно-прогностические подразделения Росгидромета, органы государственного управления, службы федеральных министерств и ведомств, институты Сибирского отделения Российской академии наук. В оперативном режиме выполняется наблюдение за территорией от Урала до Забайкалья $[1,2]$.

В ходе обработки спутниковых данных подготавливаются различные виды оперативной продукции (например, метеорологическая информация), а также осуществляются наблюдения за различными объектами и явлениями, такими как ледовый и снежный покровы, сельскохозяйственные посевы, паводковая и пожароопасная обстановки, ареалы загрязнений вокруг промышленных городов.

\section{Возможности использования спутниковых данных при решении задач сельскохозяйственной направленности}

Совместное использование спутниковых измерений характеристик растительного покрова, метеорологических данных, статистических данных об урожайности и космических изображений позволило создать технологию оперативного мониторинга состояния посевов на юге Западной Сибири. Данная технология включает в себя два взаимосвязанных вида работ: прогнозирование урожайности яровой пшеницы и оценку состояния посевов зерновых культур. С 2005 г. в СЦ ФГБУ «НИЦ «Планета» ведутся работы по прогнозированию урожайности яровой пшеницы на территории Новосибирской области, а в 2014 г. были произведены первые расчеты прогноза урожайности яровой пшеницы для Алтайского края. С 2012 г. начаты работы по оценке состояния посевов зерновых культур по трём градациям, принятым в агрометеорологии: хорошее, удовлетворительное и плохое состояние посевов. Объектами исследования являются сельскохозяйственные угодья Новосибирской, Кемеровской, Омской областей и Алтайского края. Результатом данных работ служат карты оценки состояния посевов, которые позволяют осуществлять в течение всего вегетационного периода мониторинг состояния посевов зерновых культур.

Устойчивое функционирование спутниковых систем (таких как Terra, Landsat) даёт возможность использовать в работе как оперативные, так и архивные данные. Для охвата больших территорий в оперативной работе берут информацию с американского спутника Terra (спектрорадиметр MODIS) с пространственным разрешением 250 м и шириной полосы съёмки в 2300 км.

$$
-727-
$$


Ежедневный съём одной и той же территории позволяет применять спутниковые данные для решения задач по регулярному мониторингу сельскохозяйственных культур. Для проведения исследований, требующих большей детальности, удовлетворяет информация с космических аппаратов (КА) Landsat, обеспечивающих съёмку земной поверхности с пространственным разрешением 30 м [3]. При обработке спутниковых данных нужны такие программные продукты, как ArcGIS, ENVI, SDIM и др.

С использованием спутниковой информации с KA Landsat в программном комплексе ArcGIS создаются векторные схемы внутрихозяйственного землеустройства для тестовых хозяйств (рис. 1). На данных схемах отображаются следующие элементы: поля, населённые пункты, дороги, водоёмы, колки. Поля делятся на рабочие участки, внутри которых расставляются реперные точки, каждой из которых присваивается своё уникальное значение (в атрибутивной информации указывается принадлежность к району, хозяйству и порядковый номер точки). Все реперные точки вносятся в общую базу данных и служат в дальнейшем для автоматических измерений значения вегетационного индекса. Полученные значения используются потом при расчетах прогностической урожайности и при выполнении мониторинга состояния посевов.

Исходя из рекомендаций главных агрономов административных районов ежегодно уточняется перечень тестовых хозяйств, по которым проводится комплекс мониторинговых работ в течение вегетационного периода. По каждому конкретному хозяйству формируются схемы размещения сельскохозяйственных культур на полях, на основе которых ведутся наблюдения за определенными культурами с момента появления первых всходов и до окончания вегетационного периода. Для расчета прогноза урожайности необходимы как минимум три измерения

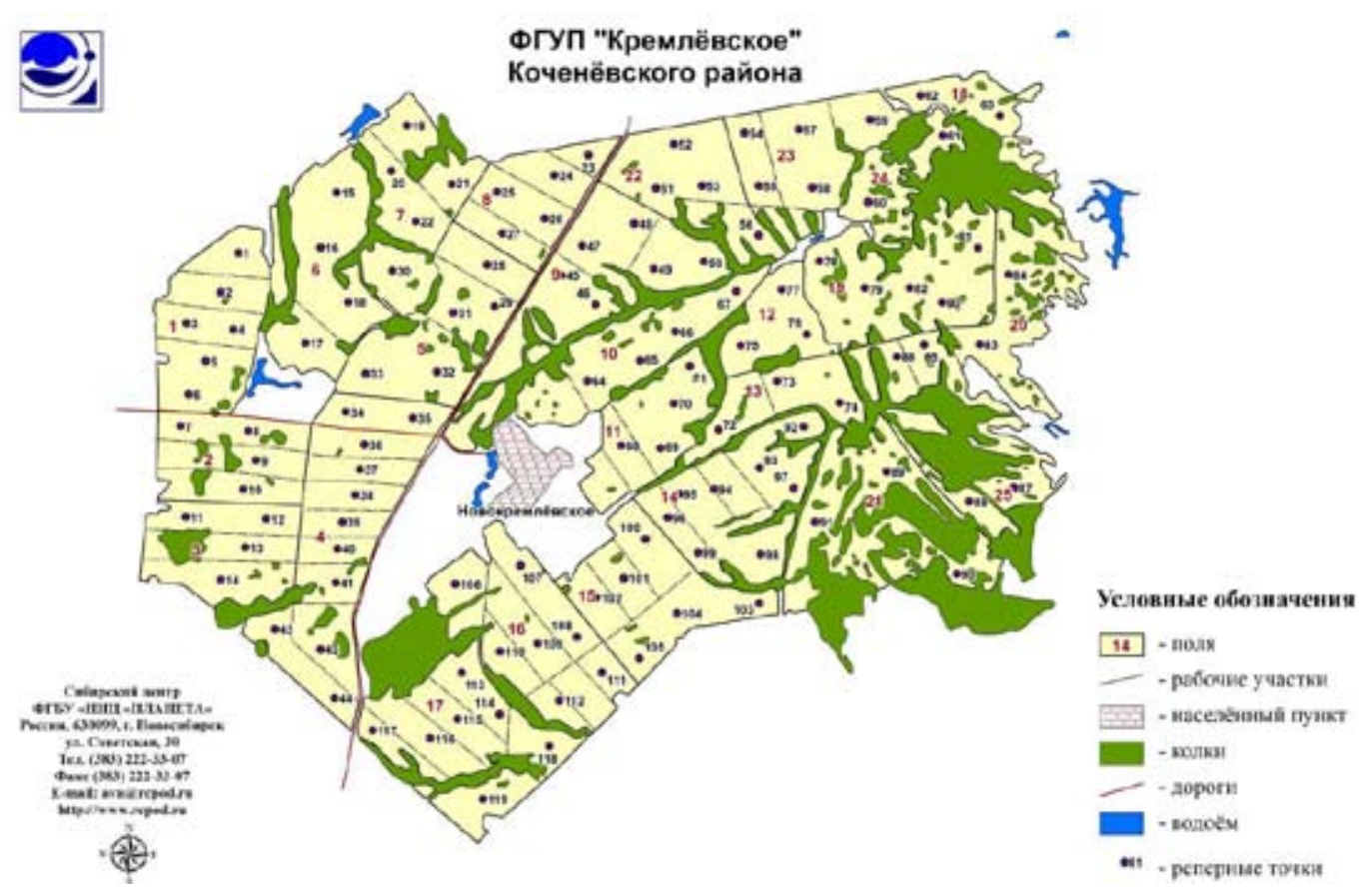

Рис. 1. Схема внутрихозяйственного землеустройства ФГУП «Кремлёвское» Коченёвского района Новосибирской области 
значений нормализованного относительного индекса вегетации (NDVI) на каждом поле. Завершающим этапом проведения наблюдений служит расчет урожайности яровой пшеницы по каждому отдельному полю, в среднем по хозяйству, а также по каждому исследуемому району. Полученные результаты передаются руководителям районных администраций Новосибирской области и руководителям хозяйств. Помимо этого подготавливается общая сводная таблица с рассчитанными значениями урожайности по всем районам области, которая передаётся в отдел агрометеорологических прогнозов ФГБУ «Западно-Сибирского УГМС» и учитывается в дальнейшем при составлении сведений о балансе зерна по России.

Для расчёта прогностической урожайности яровой пшеницы используется программный комплекс SDIM (System of Databases and Imitating Modeling), реализующий американскую модель биопродуктивности EPIC (автор Dr. Williams). Адаптация модели к агроклиматическим условиям нашего региона выполнялась Югорским НИИ информационных технологий в 2004 г. на основе применения метеоданных и данных о фактической урожайности культур за 20 лет [4]. Предварительный прогноз урожайности яровой пшеницы рассчитывают в конце июня, окончательный прогноз - до 20 июля, а в период с 15 по 20 августа делают корректировку прогноза.

Основным параметром для расчета прогноза урожайности в программном комплексе SDIM служит индекс NDVI, рассчитываемый по снимкам с KА Terra. Кроме того, для осуществления расчётов в программный комплекс вносят даты сева и предварительные даты уборки урожая (индивидуально для каждого поля), а также вводят агрометеорологические параметры (для каждого района): максимальную и минимальную температуру воздуха, суммарные суточные осадки, относительную влажность воздуха, среднюю скорость ветра, суммарную солнечную радиацию. По данным климатическим параметрам созданы ежегодно обновляемые базы данных. В настоящий момент информация по Новосибирской области (содержит данные с 1985 г.) и Алтайскому краю (содержит данные с 1999 г.) поступает с 32 и 31 метеостанции соответственно. Статистические данные позволяют определять год-аналог по климатическим параметрам и исходя из этого корректировать окончательный прогноз [5]. Оценкой качества выполненной работы служит оправдываемость прогноза, которая рассчитывается после получения из Министерства сельского хозяйства данных о фактической урожайности. Наши исследования показали, что существует стабильная взаимосвязь индекса вегетации и фактической урожайности. Коэффициент корреляции, посчитанный по фактической урожайности и максимальным значениям индекса вегетации, составил 0,83 . В таблице приведены результаты оценки качества прогнозирования урожайности яровой пшеницы в Новосибирской области с 2005 по 2013 г.

На начальном этапе формирования технологии мониторинга посевов были выбраны тестовые хозяйства с разным уровнем интенсивности земледелия в соответствии с агрометеорологическим районированием. Накопленная статистика измерений индекса вегетации на полях в тестовых хозяйствах в период с 2005 по 2011 г., созданные базы метеоданных и данных о фактической урожайности с 1985 г., архивная информация с КА Теrra послужили основой для реализации работ по оценке состояния посевов.

В нашем регионе большой процент земель не используется под сельскохозяйственные посевы. После проведения аналитических работ на основе имеющихся данных для практической реа-

$$
-729-
$$


Таблица. Результаты расчета оправдываемости прогноза по хозяйствам и районам Новосибирской области

\begin{tabular}{|c|c|c|c|c|c|c|c|c|c|c|}
\hline & \multicolumn{9}{|c|}{ Годы } & \multirow{2}{*}{$\begin{array}{c}\text { Средняя } \\
\text { оправдываемость } \\
\text { прогнозов, } \\
\%\end{array}$} \\
\hline & ஜ̊ & ๖̊ & 홍 & $\stackrel{\infty}{\stackrel{0}{\circ}}$ & 응 & $\stackrel{\circ}{\stackrel{0}{\circ}}$ & $\overline{\bar{\sigma}}$ & $\underset{\sim}{\stackrel{ }{~}}$ & $\stackrel{m}{\stackrel{\sim}{\nu}}$ & \\
\hline $\begin{array}{l}\text { Количество } \\
\text { административных } \\
\text { районов }\end{array}$ & 15 & 15 & 17 & 18 & 19 & 19 & 19 & 18 & 17 & \\
\hline Количество хозяйств & 26 & 30 & 36 & 38 & 50 & 36 & 56 & 41 & 39 & \\
\hline $\begin{array}{l}\text { Количество полей в } \\
\text { хозяйствах }\end{array}$ & 161 & 201 & 236 & 229 & 277 & 181 & 528 & 325 & 297 & \\
\hline $\begin{array}{l}\text { Оправдываемость } \\
\text { прогноза в } \\
\text { хозяйствах ( \%) }\end{array}$ & 88 & 82 & 97 & 84 & 90 & 97 & 87 & - & 74 & 87,4 \\
\hline $\begin{array}{l}\text { Среднерайонный } \\
\text { прогноз (количество } \\
\text { районов) }\end{array}$ & - & - & 6 & 16 & 30 & 30 & 30 & 30 & 30 & \\
\hline $\begin{array}{l}\text { Оправдываемость } \\
\text { среднерайонной } \\
\text { урожайности ( \%) }\end{array}$ & - & - & 85 & 84 & 88 & 87 & 85 & 69 & 66 & 80,6 \\
\hline
\end{tabular}

лизации идеи оценки состояния посевов была поставлена задача выделить по материалам космической съёмки пахотные земли на исследуемые территории. По информации с KA Landsat c применением программного комплекса ArcGIS были построены маски неиспользуемых земель.

Спутниковое изображение с КА Terra c рассчитанным индексом вегетации совмещается с масками облачности и неиспользуемых земель. Далее при помощи полученных ранее пороговых значений NDVI все оставшиеся точки снимка разбивают на три градации и окрашивают в соответствующий цвет: зелёный, если значение в этой точке попало в интервал, соответствующий хорошему состоянию посевов, жёлтый - удовлетворительному, красный - плохому. Полученное изображение совмещается с векторными слоями, отображающими элементы гидрографии, административные границы района и наиболее крупные населенные пункты. Карты оценки формируются по каждому свободному от облачности спутниковому изображению с момента появления всходов и до окончания вегетационного периода. Полученные карты позволяют в оперативном режиме наглядно оценить состояние посевов юга Западной Сибири с процентным соотношением каждой из трех градаций. Данные карты в оперативном режиме передаются в отделы агрометеорологических прогнозов ФГБУ «Западно-Сибирского УГМС», а также размещаются на сайте организации www.rcpod.ru в разделе «Оперативная продукция» (Мониторинг состояния посевов).

\section{Результаты оперативного мониторинга 2014 г.}

В 2014 г. в Новосибирской области расчет урожайности яровой пшеницы проводился на 413 полях в 36 хозяйствах. Прогноз урожайности того года в Новосибирской области в южных районах (Купинский, Карасукский, Краснозёрский) составил от 4 до 8 ц с гектара. Значительно выше прогнозировалась урожайность в восточной зоне (Тогучинский, Колыванский, Искитим- 
ский и Маслянинский районы). Среднее прогнозное значение урожайности яровой пшеницы по хозяйствам Новосибирской области составило около 13 ц с гектара. Неблагоприятные для развития культур погодные условия этого года нашли своё отражение в низких показателях урожайности. Очень низкие температуры мая сдерживали ход посевных работ на полях, поэтому в некоторых хозяйствах посевная закончилась только к 10 июня. Холодная погода мая и первой декады июня спровоцировала задержку роста и развития сельскохозяйственных культур. Установление с 14 июня жаркой погоды и недостаточное увлажнение почвы тоже сдерживали развитие посевов.

Для сравнительной оценки сложившейся ситуации были проанализированы результаты наблюдений за последние четыре года и построены графики развития пшеницы, отражающие ход значений индекса вегетации (рис. 2). Погодные условия 2012 и 2013 гг. также негативно сказались на развитии культур (условия сильной засухи в один год и неблагоприятные условия уборки урожая - в другой), что отразилось в низкой урожайности в эти годы. За последние четыре года погодные условия в 2011 г. оказались наиболее оптимальными для нормального развития посевов, что нашло отражение в полученном графике.

Параллельно работам по подготовке прогноза урожайности велась работа по оценке состояния посевов зерновых культур. За период 2014 г. было подготовлено 5 карт оценки по Новосибирской области, по 4 карты для Кемеровской области и Алтайского края, 2 карты для Омской области. Для примера можно привести карты оценки, полученные для территории Новосибирской области (рис. 3).

По результатам обработки информации за 27 июня в Новосибирской области плохому состоянию посевов соответствует $7 \%$ обрабатываемых земель, удовлетворительному - 50 \%, а хорошему $-43 \%$. На 11 июля плохому состоянию посевов соответствует $5 \%$, удовлетворительному $-65 \%$, а хорошему - 30 \% посевов. В худшем состоянии находились посевы в южных районах области (Карасукский, Баганский, Купинский, Краснозёрский и др.), в восточной части области состояние посевов было лучше, что нашло отражение на полученных картах, а также в результатах расчетов прогноза.

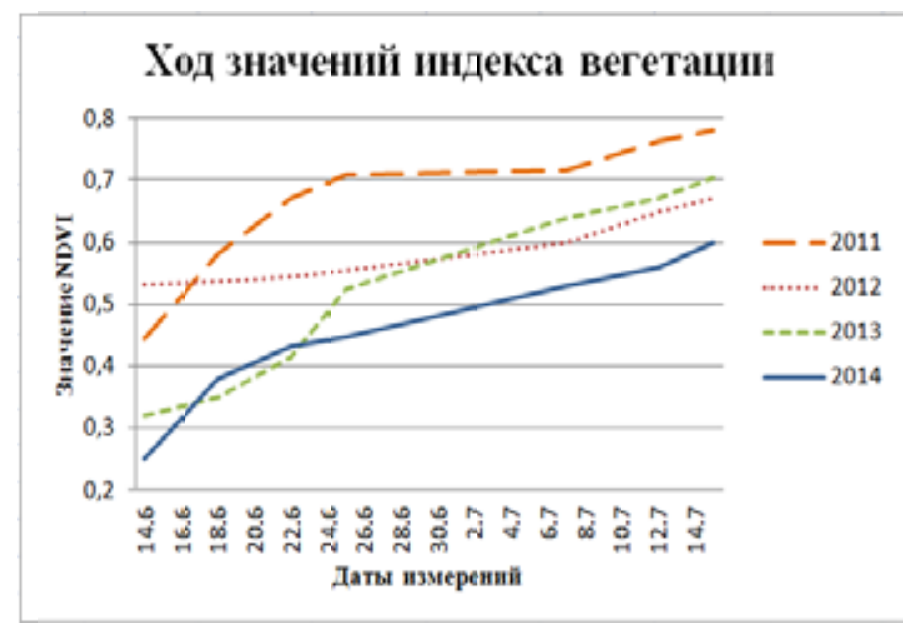

Рис. 2. Ход значений индекса вегетации 


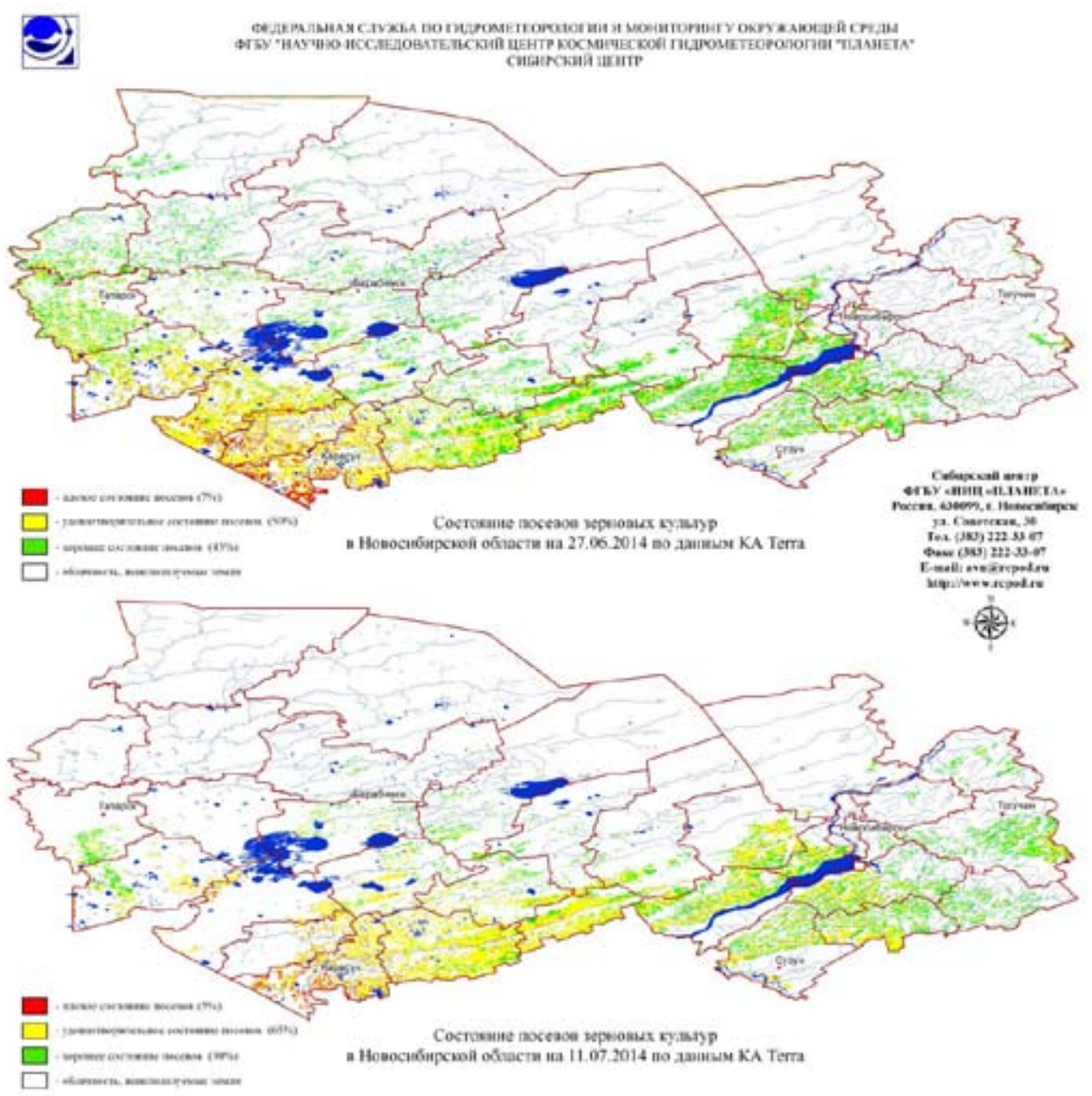

Рис. 3. Карты оценки состояния посевов зерновых культур, Новосибирская область, 27.06.2014 и 11.07.2014

\section{Заключение}

Разработанная в СЦ ФГБУ «НИЦ «Планета» технология мониторинга состояния посевов зерновых культур подтверждает свою работоспособность, о чём можно сделать вывод, исходя из сравнения полученных результатов со статистическими данными и данными наземных агрометеорологических маршрутных обследований. Использование спутниковых данных позволяет облегчить трудоёмкий процесс наземных способов сбора данных, дополняет его, а порой и заменяет при невозможности проведения наземных измерений на труднодоступных территориях и позволяет тем самым упростить задачу мониторинга состояния сельскохозяйственных культур на обширных территориях.

\section{Список литературы}

[1] НИЦ «Планета»: [сайт]. URL: http://planet.iitp.ru/index1.html

[2] Сибирский центр «НИЦ «ПЛАНЕТА»: [сайт]. URL: http://www.rcpod.ru/index.html 
[3] Кулик Е.Н. Оперативный космический мониторинг: вчера, сегодня, завтра // Интерэкспо ГЕО-Сибирь-2012. VIII Междунар. научн. конгр., 10-20 апреля 2012 г., Новосибирск: Междунар. науч. конф. «Дистанционные методы зондирования Земли и фотограмметрия, мониторинг окружающей среды, геоэкология»: сб. материалов в 2 т. Т. 2. - Новосибирск: СГГА, 2012. C. 134-139.

[4] Брыксин B.M. Применение адаптированной модели биопродуктивности ЕРІС и космоснимков MODIS для прогнозирования урожайности зерновых культур на территории Западной Сибири // Вестник НГУ. Серия: Информационные технологии. НГУ, 2007. Т. 5. Вып. 1. C. 20-26.

[5] Сахарова Е.Ю., Сладких Л.А., Захватов М.Г. Спутниковый мониторинг состояния посевов и прогнозирование урожайности зерновых культур на юге Западной Сибири // Интерэкспо ГЕО-Сибирь-2014. Х Междунар. науч. конгр., 8-18 апреля 2014 г., Новосибирск: Междунар. науч. конф. «Дистанционные методы зондирования Земли и фотограмметрия, мониторинг окружающей среды, геоэкология»: сб. материалов в 2 т. Т. 1. Новосибирск: СГГА, 2014. C. $67-72$. 